\title{
Authors' Reply to Ahmad SR: “Adverse Drug Reaction Reporting by Patients: An Overview of Fifty Countries"
}

\author{
Florence Margraff • Delphine Bertram
}

Published online: 21 November 2014

(C) Springer International Publishing Switzerland 2014

First of all, we thank Dr. Syed Rizwanuddin Ahmad for his well-advised comments [1] and for offering us the opportunity to clarify a number of points from our work [2].

As Dr. Ahmad mentioned in his letter to the editor, even if Australia was one of the first countries to accept patient adverse drug reaction (ADR) reports in 1964, it was the USA that first initiated and developed a drug ADR surveillance programme, in 1956-a few years after the chloramphenicol-associated blood dyscrasia issue. This programme, launched by the US Food and Drug Administration (FDA), started with six hospitals at the beginning, which had to report ADRs on a monthly basis, and then the programme was rapidly expanded to other hospitals in the 1960s [3].

Dr. Ahmad underlined the fact that in the USA, in 2013, the direct patient reporting to health authorities was around $2.5 \%$, the remainder being indirect reporting. We agree that our paper should have clearly mentioned if the ADR reporting by a patient is direct, i.e. reporting to a health authority (or to a regional pharmacovigilance centre) or indirect via a marketing authorization holder (MAH). The percentage given in Table 1 (the patient reports column) in our paper was, most of the time, direct reporting, except for the USA and Canada, where the majority of ADR reports by patients/consumers are received indirectly via the MAH [4].

Another point addressed by Dr. Ahmad is clarification of the pathway of reporting done by patients or consumers. When our paper mentioned that "direct patient reporting systems exist in 44 countries out of the 50 surveyed countries", it meant that National Health Competent Authorities (NCAs) have implemented tools to directly

F. Margraff · D. Bertram $(\bowtie)$

Délégation à la Recherche Clinique et à l'Innovation, Hospices

Civils de Lyon, Lyon, France

e-mail: delphine.bertram@chu-lyon.fr receive ADR reports from patients or healthcare professionals (HCPs). Moreover, 27 countries (61\%) provide customized patient forms for direct reporting to NCAs, which differ from those intended to be used by HCPs and are easier to understand and complete. However, even if the NCAs of these 27 countries specially provide a separate direct ADR reporting system for patients or consumers, this system is not really dissociated from that set up for HCPs. Indeed, most of the time, the NCA website offers the possibility to report an ADR with a binary input: report as a patient or as an HCP. The direct patient ADR reporting is also subject to the same minimum reporting criteria required by the pharmacovigilance to be validated.

Ultimately, the question of direct or indirect reporting (via an MAH) of a ADR by a patient can be raised and, even if it is well established that direct patient reporting to the NCA represents real added value for pharmacovigilance, the essential point is the fact that patients or consumers report ADRs.

Funding and conflicts of interest No sources of funding were used in the preparation of this study. Florence Margraff and Delphine Bertram have no conflicts of interest that are directly relevant to the content of this study.

\section{References}

1. Ahmad SR. Comment on: adverse drug reaction reporting by patients: an overview of fifty countries. Drug Saf. 2014. doi:10. 1007/s40264-014-0241-0

2. Margraff F, Bertram D. Adverse drug reaction reporting by patients: an overview of fifty countries. Drug Saf. 2014;37(6):409-19.

3. Ahmad SR, Goetsch RA, Marks NS. Spontaneous reporting in the United States. In: Strom BL, editor. Pharmacoepidemiology, chapter 9. Chichester: Wiley; 2005. pp. 135-159.

4. Van Hunsel F, Härmark L, Pal S, Olsson S, Van Grotheest K. Experiences with adverse drug reaction reporting by patients: an 11-country survey. Drug Saf. 2012;35(1):45-60. 